Rhode Island College

Digital Commons @ RIC

$5-1-2013$

\title{
An Exploration of the Barriers to Diabetes Management Among West African Immigrants in the United States
}

Oluseyi Grace Abioye-Akanji

Rhode Island College

Follow this and additional works at: https://digitalcommons.ric.edu/etd

Part of the Nursing Commons

\section{Recommended Citation}

Abioye-Akanji, Oluseyi Grace, "An Exploration of the Barriers to Diabetes Management Among West African Immigrants in the United States" (2013). Master's Theses, Dissertations, Graduate Research and Major Papers Overview. 214.

https://digitalcommons.ric.edu/etd/214

This Major Paper is brought to you for free and open access by the Master's Theses, Dissertations, Graduate Research and Major Papers at Digital Commons @ RIC. It has been accepted for inclusion in Master's Theses, Dissertations, Graduate Research and Major Papers Overview by an authorized administrator of Digital Commons @ RIC. For more information, please contact digitalcommons@ric.edu. 


\title{
AN EXPLORATION OF THE BARRIERS TO DIABETES MANAGEMENT AMONG WEST AFRICAN IMMIGRANTS IN THE UNITED STATES
}

by

\author{
Oluseyi Grace Abioye-Akanji \\ A Major Paper Submitted in Partial Fulfillment \\ of the Requirements for the Degree of \\ Masters of Science in Nursing \\ in \\ The School of Nursing \\ Rhode Island College
}

2013 


\begin{abstract}
Purpose: To explore the barriers to diabetes management among West African immigrants living in Rhode Island.

Study Design and Methods: Semi-structured interviews with adults $(\mathrm{N}=5)$; men $(\mathrm{n}=2)$, women ( $n=3)$, Nigerian $(n=3)$, Liberian $(n=1)$, and Ghanaian $(n=1)$ ages $\geq 18$ with Type 1 or Type 2 diabetes, living in Rhode Island. Demographic information of the participants was obtained using a questionnaire. Interviews were conducted by the researcher and lasted approximately 50 minutes, and were scheduled to accommodate participants' needs. Interviews were audio-taped and statements of the study participants were recorded. Subjects were redirected to clarify responses when necessary. Content analysis and coding, as proposed by Miles and Huberman (1994), were completed. Eight pertinent themes were identified.

Results: All participants had Type 2 diabetes and reported various barriers to diabetes management: (1) financial difficulties, (2) poor dietary habits, (3) non adherence to daily maintenance, (4) cultural attachment to traditional management of diabetes, (5) cultural beliefs, (6) negative relationship with primary care doctor, (7) non-adherence to medication regimen, and (8) their practitioner's inadequate knowledge of cultural care. Clinical Implications: These findings revealed that barriers exist for suitable diabetes management by some West African immigrants living in RI. Reducing the risk for complications, morbidity, and mortality can only occur with reduction of identified barriers.
\end{abstract}




\section{Acknowledgement}

I owe my deepest gratitude to the Almighty God for giving me the grace to complete this thesis. Thanks to all West African immigrants in Rhode Island who participated in the study, because without you this thesis would have remained a dream. Thanks to the African Alliance of Rhode Island (AARI) which is committed to the well being of this population, and allowed me to use its facility to recruit participants. To the director of AARI "Julius Kolawole," thank you for your support and commitment to the success of this project. To Mary Jean Francis, VP Performance Improvement of the Providence Community Health Center, I thank you for your great contribution. To Dr. Joanne Costello, thank you for sharing your expertise.

Dr. Cynthia Padula, Thank you for your encouragement and your unrelenting support for this project which contributed to my success in the graduate program. Without your guidance and persistent help, this thesis would not have been possible.

To my project supervisor, Dr. Peggy Matteson, thank you for your guidance, support and efforts to make the success of this project a reality. Your ideas and contributions have been absolutely invaluable. To my advisor, Professor Margaret Mock, thank you for your guidance and support over the years and your contributions to this project.

To my sister, Dr. Funke Bolujoko, thank you for your love, financial support, and prayers. My dear husband and my wonderful kids, your love and smiling have kept me inspired. Thank you for your support and for hanging in there with me during the difficult time. We did it!! 


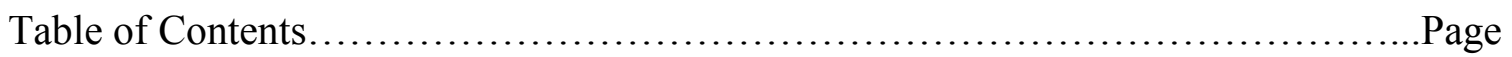

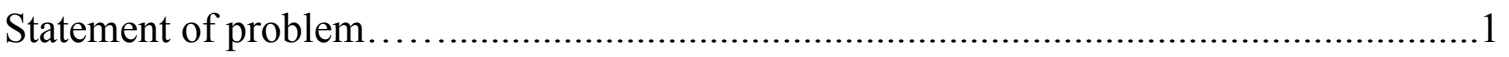

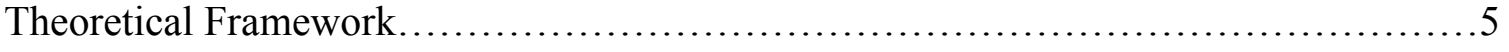

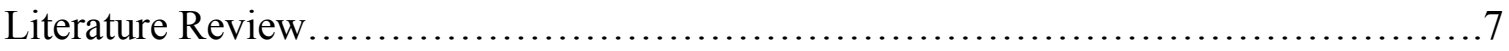

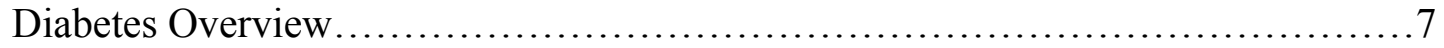

Epidemiology of Diabetes.................................................... 8

Diabetes Management....................................................... 12

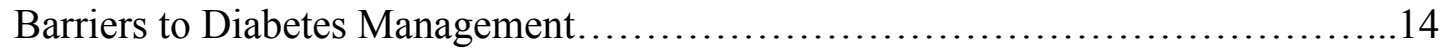

Factors Related to Barriers to Diabetes Management among West Africans in

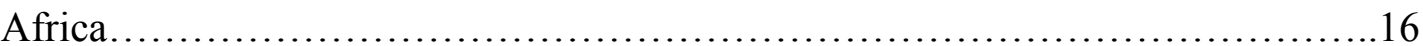

Factors Related to Barriers to Diabetes Management among African American

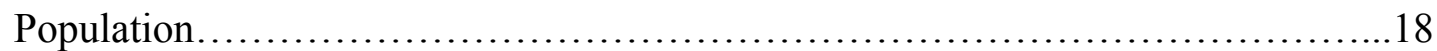

Factors Related to Barriers to Diabetes Management among African Immigrants in

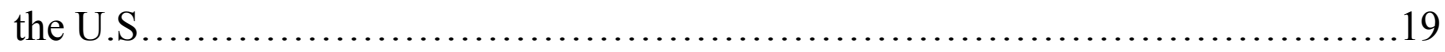

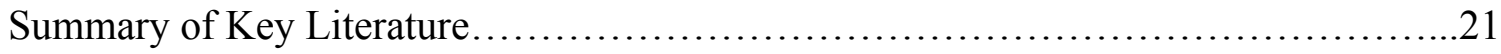

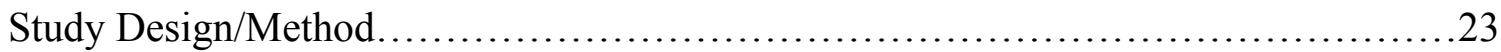

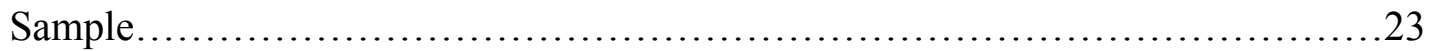

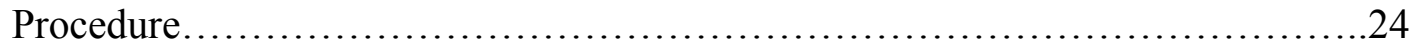

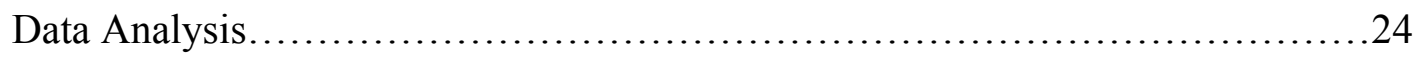

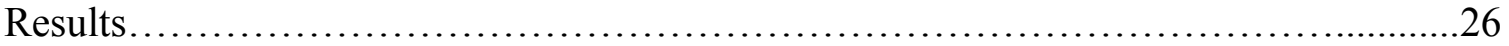




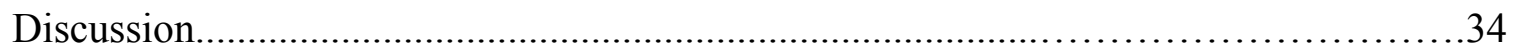

Conclusions and Implications for Advanced Nursing Practice........................42

References..............................................................45

Appendix A................................................................ 53

Appendix B.......................................................... 56

Appendix C............................................................. 58 


\section{Statement of Problem}

The United States (U.S.) population has grown and diversified both racially and ethnically. In 2000, the U.S. population was estimated to be 291 million, as compared to 308 million in 2010, signifying an increase of $9.7 \%$. Approximately $36.3 \%$ of the U.S. population currently belongs to a racial or ethnic minority group, including American Indian or Alaska Native, Asian American, Black or African American, Hispanic or Latino, and Native Hawaiian or other Pacific Islander. The population of Blacks or African Americans is estimated at over 42 million, making up $13.6 \%$ of the total U.S. population (U.S. Census Bureau, 2010).

From 2000-2010, the African-born population in the U.S. grew from 881,300 to 1.6 million (Migration Information Policy [MIP], 2011). In 2009, African immigrants accounted for $3.9 \%$ of all immigrants in the U.S. The highest number of African immigrants has been reported to be from West Africa, constituting about $36.3 \%$ of all African immigrants in the U.S. Western Africa countries include Benin, Burkina Faso, Cape Verde, Gambia, Ghana, Guinea, Guinea-Bissau, Ivory Coast, Liberia, Mali, Mauritania, Niger, Nigeria, Senegal, Sierra Leone, St Helena, and Togo. Nigeria, Ghana, and Liberia are among the West African countries with the most immigrants to the U.S. (MIP, 2012).

Diabetes poses a significant public health challenge for the U.S. It is estimated that diabetes affects 25.8 million people, or $8.3 \%$ of the U.S. population (Center for Disease Control and Prevention [CDC], 2011). Certain groups such as African-Americans, Hispanic Americans, Asian Americans, and Pacific Islanders tend to be more vulnerable 
to developing diabetes. An estimated 2.3 million African Americans, or almost 11\%, have Type 1 or Type 2 diabetes with Type 2 being more prevalent (The African American Community Health Advisory Committee [AACHAC], 2009). African Americans are 1.7 times more likely to develop diabetes than Caucasian Americans (AACHAC, 2009). This number of diagnosed cases of diabetes is continuing to steadily increase among African Americans. This population is more likely to suffer complications from diabetes, such as end-stage renal disease and lower extremity amputations (U.S. Office of Minority Health, 2010). In 2008, African American men were 2.7 times as likely to suffer from end-stage renal disease as compared to nonHispanic White men. In 2009, African Americans were 2.2 times as likely as nonHispanic Whites to die from diabetes (Office of Minority Health). In 2010, age-adjusted prevalence of visual impairment was 21.6 per 100 of African American adults with diabetes (CDC, 2012). Eradicating differences in diabetes outcomes was one of the six goals of the U.S. Department of Health and Human Services' Initiatives to Eliminate Racial and Ethnic Disparities in Health (1999). However, the preceding data show that this goal has not been fully realized.

The number of people with diabetes in all African countries in 2006 was 10.4 million and is expected to increase to 18.7 million by 2025 . The undiagnosed cases are estimated to be as high as $60 \%$ to $80 \%$ in Cameroon, Ghana, and Tanzania. The World Health Organization (WHO) estimated that in the year 2000, about 113,000 people in Africa died from diabetes, 561,600 were permanently disabled, and 645,800 experienced temporary disablement (WHO, 2008). According to Nwankwo, Nandy, \& Nwankwo 
(2010), morbidity and mortality from diabetes is very high in Nigeria due to poor management and noncompliance with management guidelines. Nwankwo et al. (2010) identified factors that influence diabetes management among diabetes patients in southeast Nigeria. Ninety-three point six percent of the 47 patients interviewed lacked basic knowledge of diabetes management or care and reported inability to visit the doctor except when manifesting serious symptoms or complications.

Diabetes rates among African immigrants in the U.S. have not been separately reported as to area of origin; accordingly, there is no specific data for West African immigrants, the focus of this research. The existing data tend to categorize blacks in general and foreign-born blacks in particular as a homogenous group (Shepard, 2008). Based on the existing studies and data, this author noted that African immigrants are generally grouped together as Black or African Americans. Grouping immigrants together into one or a few large categories may mask genetic, environmental, social, and cultural variations in relation to health between ethnic groups in the U.S. (Shepard, 2008). Anecdotal evidence gathered from various West African communities in the U.S. suggests that diabetes threatens the health of this population. This researcher, being a West African immigrant and part of the community in Rhode Island, hypothesizes that the rate at which diabetes complications arise in this community is high; the occurrences of kidney failure, amputation, cardiovascular disease, and death resulting from diabetes complications are apparent. However, there are no existing data supporting this hypothesis. 
There is a significant gap in literature related to barriers to management of diabetes among West African immigrants. Considering the increasing growth of this group in the U.S., and based on the increased burden of diabetes and diabetes complications as evident from the previously stated data, there is a compelling need for scholarly inquiry that focuses on understanding the barriers to diabetes awareness and management among high risk populations such as West African immigrants. Understanding these barriers may inform development of tailored interventions and management of diabetes in this diverse community. The purpose of this study is to explore the barriers to diabetes management among West African immigrants living in Rhode Island. 


\section{Theoretical Framework}

Madeleine Leininger developed the theory of Cultural Care Diversity and Universality through her research in the field of anthropology, ethnography, and nursing (Leininger, 2002). Leininger (1993) defines culture as the "learned, shared, and transmitted values, beliefs, norms, and life ways of a particular group that guide thinking, decisions, and actions in patterned ways and the ways of life of the members of a society, or of groups within a society"( p. 9). The purpose of Leininger's theory is to provide a basis from which to generate knowledge related to the nursing care of people who value their cultural heritage and ways of life and to use that knowledge to provide culturally congruent nursing care to various cultural groups (Leininger, 1988). As stated by Leininger (1978), there are many ways by which different cultures explain normal and abnormal health. Health must be studied and defined within the context of specific cultures. It is safe to assume that the way an individual understands health and disease such as diabetes is culturally influenced. This study will incorporate Leininger's cultural care diversity conceptual framework as the basis from which to explore barriers to diabetes management with a focus on West African immigrants.

Models of nursing decision-making and subsequent actions, cultural care preservation, cultural re-patterning, and cultural care accommodation were proposed by Leininger (1988) to facilitate the provision of culturally congruent care. Cultural care preservation refers to nursing actions that safeguard cultural practices of the patient to maintain health and care. Within diabetes care, this view may consist of considering what the diagnosis means to the individual and/or family, and perhaps how the person can 
continue to eat traditional foods without a negative impact on blood glucose levels. Cultural re-patterning relates to changing client behavior to promote health and care. In diabetes care, this could mean having discussions with patients about ways to cut back on smoking tobacco, with the goal of eventually quitting. Cultural care accommodation refers to flexible adaptation of nursing actions or negotiation to promote health. In diabetes care, this may take the form of talking with patients about ways they could incorporate physical activity into their daily routines. The ultimate goal of clinicians working with immigrant populations of diverse cultures is to provide culturally appropriate care to individuals, families and the communities. Batts-Turner (2007) advocated that " ... as complicated as the disease process, and as much as we need to provide basic health care, we need to truly understand the cultural context in which the minority population have to take care of their disease and we must work from their priorities, otherwise we are not going to be able to provide an appropriate level of care regardless of our tools" (p. 3). In order to stem the increasing prevalence and complications of diabetes in the West African immigrant population, understanding how their cultural characteristics impact diabetes management should be a public health priority. 


\section{Literature Review}

The Medline, CINAHL, and WorldCat databases were searched using the keywords “diabetes," "African Americans and diabetes," "African immigrants and diabetes," "West African immigrants and diabetes" in combination with at least one of the following: "barriers to diabetes management," "cultural beliefs," or "complications." Additional articles were retrieved by reviewing the references of the selected literature. Studies that identified barriers to diabetes management among West African immigrants were the major focus of this literature review.

\section{Diabetes: Overview}

Diabetes Mellitus (DM) is a group of metabolic diseases whose common feature is a high level of blood glucose resulting from defects in insulin production, insulin action, or both (CDC, 2011). DM is a serious disease which, if not properly managed, can be life threatening and associated with long-term complications that can affect every system of the body. DM has two primary forms: Type 1 (T1DM), also known as insulin-dependent (IDDM) or juvenile-onset diabetes; and Type 2 (T2DM), also known as non-insulindependent (NIDDM) or adult-onset diabetes (CDC, 2007).

T1DM occurs as the result of autoimmune disorder which damages the pancreas, ultimately leading to reduced or absent insulin secretion. T1DM accounts for $5-10 \%$ of those diagnosed with DM. T2DM is caused by impaired glucose metabolism, and often as a result of obesity, physical inactivity, older age, family history of diabetes, and race/ethnicity. T2DM accounts for $90-95 \%$ of those diagnosed with DM in the U.S. Together both T1DM and T2DM are the seventh leading cause of death in the U.S., 
primarily from diabetes-related cardiovascular disease. Additionally, diabetes is the leading cause of kidney failure, non-traumatic amputations, and blindness among adults in the U.S. (CDC, 2011).

\section{Epidemiology of Diabetes}

Diabetes affects 25.8 million children and adults in the U.S. Approximately 18.8 million people are diagnosed with diabetes and 7.0 million people are undiagnosed. In 2010, 1.9 million new case of diabetes were diagnosed in people aged 20 years and older (CDC, 2011).

Boyle, Thompson, Gregg, Baker, \& Williamson (2010) conducted a study using a series of dynamic models to project the future burden of diabetes prevalence among U.S. adults. They used data from the U.S. Census Bureau and the CDC. Census data were based on the 2000 census and included estimates of mortality rates, net migration, and births from 2008 through 2050. CDC data included estimates and standard errors of incidence rates of diagnosed diabetes for the U.S. adult population (aged 18-79 years) from 1989 through 2007. A transition matrix based on a literature review estimates of the rates of transition from having no diabetes, pre-diabetes, and undiagnosed diabetes to having diagnosed diabetes, as well as the risk of mortality associated with different glycemic and diabetes states, were used. Based on the findings, Boyle et al. (2010) projected that annually diagnosed new cases of diabetes will increase to about 15 cases per 1000 in 2050, compared to the eight cases per 1000 reported in 2008. Both diagnosed and undiagnosed cases were projected to increase from $14 \%$ in 2010 to $21 \%$ of the U.S. adult population in 2050. Important to the purpose of this paper, Boyle et al.(2010) also 
found that increased incidence in higher-risk minority groups was a contributing factor to the projected increase.

Oza-Frank and Venkat Narayan (2010) conducted an analytical study to examine the prevalence of diabetes among U.S. immigrants by region of birth. Data from 1997 to 2005 on 34,456 U.S. immigrant adult respondents from the National Health Interview Survey (NHIS) were analyzed. The nine regions of birth categories provided by National Center for Health Statistics (NCHS) were: (1) Mexico/Central America/Caribbean Islands, (2) South America, (3) Europe, (4) Russia (and former Soviet Union areas), (5) Africa, (6) the Middle East, (7) Indian subcontinent, (8) Central Asia, and (9) Southeast Asia. The survey included approximately 43,000 households and about 106,000 persons annually. One randomly selected adult per household was asked to complete the sample. The survey elicited detailed information on health care services, behavior, and health status, including height, weight, and diabetes. African men ranked second in the prevalence of diabetes as illustrated in Table 1.0, while African women ranked third when compared with other regions as illustrated in Table 1.1. 
Table 1.0

Prevalence of diabetes among men by region of birth

\begin{tabular}{|l|l|l|}
\hline \multicolumn{1}{|c|}{ Region of Birth } & \% of Immigrants & $\mathbf{9 5 \%}$ Cl \\
\hline Europe & 2.85 & $(1.94,3.75)$ \\
\hline Mexico & 5.29 & $(4.64,5.94)$ \\
\hline Southeast Asia & 5.06 & $(3.22,6.90)$ \\
\hline India Subcontinent & 8.19 & $(5.15,11.23)$ \\
\hline Africa & 7.76 & $(4.39,11.13)$ \\
\hline
\end{tabular}

Table 1.1

Prevalence of diabetes among women by region of birth

\begin{tabular}{|l|l|c|}
\hline \multicolumn{1}{|c|}{ Region of Birth } & \% of Immigrants & $\mathbf{9 5 \%}$ Cl \\
\hline Europe & 3.04 & $(1.92,4.16)$ \\
\hline Mexico & 6.20 & $(5.48,6.93)$ \\
\hline Southeast Asia & 4.01 & $(2.39,5.61)$ \\
\hline India Subcontinent & 11.57 & $(7.06,16.08)$ \\
\hline Africa & 4.57 & $(2.39,5.61)$ \\
\hline
\end{tabular}

Abubakari, Lauder, Jones, Kirk, Agyemang, and Bhopal (2009) conducted a systematic review of literature to determine the prevalence and distribution of, and trend in, physical inactivity and diabetes in adult West African populations. Twenty-one reports were retrieved for diabetes and 15 reports were retrieved for physical inactivity. Most studies (10 for diabetes and 6 for physical activity) were conducted solely among urban populations. Results showed the prevalence of diabetes in West Africa to be 
approximately $4.0 \%$ (95\% confidence interval [CI] 2.0-9.0) in urban adults and $2.6 \%$ (95\% CI 1.5-4.4) in rural adults. Results were similar for men and women [prevalence ratio (PR) 1.36, 95\%CI 0.96-1.92]. Cumulative time trend analyses suggested an increase in the prevalence of diabetes among adults in urban West Africa, from approximately $3.0 \%(95 \%$ CI $1.0-7.0)$ to $4.0 \%(95 \%$ CI $2.0-9.0)$ over 10 years. The prevalence of physical inactivity in West Africa was 13\% (95\%CI 9.0-18.0). An association was found between physical inactivity and being older ( $\geq 50$ years) (PR 1.82, 95\%CI 1.36-2.44), being female (PR 1.62, 95\%CI 1.41-1.87), and living in an urban area (PR 2.04, 95\%CI 1.58-2.63). Abubakari et al. (2009) found that the 4\% prevalence of diabetes in this population was similar to rates in many European and other industrialized countries. It was, however, below the $9-14 \%$ prevalence reported for African origin people in the Caribbean, and the United Kingdom, and it was below the $16 \%$ prevalence reported among recent Ghanaian immigrants in Australia; westernization and duration of migration were found to account for these differences (Abubakari et al., 2009).

Jovanovic and Harrison (2004) conducted a systematic review of diabetes incidence in minority populations in the U.S. The authors used data from studies of nationally representative samples and focused on the two largest minority groups in the U.S.: African Americans and Hispanics. They found that when compared with their white counterparts, African American men were 20\% to 50\% more likely, and African American women were $100 \%$ more likely, to develop diabetes. In the third National Health and Nutrition Examination Survey (NHANES) epidemiological follow-up study, Jovanovic and Harrison (2004) reported that the 20-year age-adjusted rate of first lower 
extremity amputations for African American subjects was twice as high as in whites. The epidemiologic follow-up study showed that smaller proportions of African Americans and Mexican Americans self-monitored their blood glucose compared to whites $(27 \%$ versus $44 \%$ ), and had their cholesterol checked (62\%-68\% versus $81 \%)$. African American and Mexican American patients had worse glucose control than white patients (HbA1c $\geq 7 \% ; 58 \%-66 \%$ versus 55\%). Relevant to the purpose of this paper, excess risk of diabetes in African Americans versus non-Hispanic whites was found to be greater in women (absolute risk difference, 14.7 per 1000 person; risk ratio $=1.47)($ Jovanovic et al, 2004).

Apart from age, the profile of established risk factors for diabetes was clearly worse in African American women than in their white counterparts. African American women were noted to have fewer years of formal education, greater measure of adiposity (including elevated BMI and increased ratio of hip-waist circumference), and less physical activity during leisure time. Consequently, increased susceptibility to diabetes in African Americans appear to be related to associated risk factors rather than intrinsic biological differences, and the optimum outcome in the management of a chronic disease such as diabetes is strongly dependent on the ability of the patients to develop effective self-care (Jovanovic et al., 2004).

\section{Diabetes management}

The aims of diabetes management are to restore the altered metabolism of the person with diabetes, maintain blood glucose levels within the normal range, reduce risk factors of diabetes- related complications, prevent or delay progression of short and long- 
term complications, empower the person to self-manage their own diabetes, and restore the individual with diabetes to as independent a lifestyle as possible (Diabetes Outreach, 2009). To assist patients with diabetes management, a wellness approach to diabetes management is recommended which includes: monitoring blood sugar level and knowing the target goal, maintaining ideal body weight, monitoring food intake and knowing appropriate nutrition, maintaining physical exercise levels for 30 minutes 5 days a week, maintaining regular appointments with the health care team to check kidney function, blood pressure, cholesterol level, and yearly retinal eye examination, and appropriate safe use of pharmaceuticals (oral agents and/or insulin) (Diabetes Research Institute, 2009). It is well established that motivated individuals who understand their disease and how to manage it experience fewer complications (American Diabetes Association [ADA], 2003).

Schulze and $\mathrm{Hu}(2005)$ conducted a systematic review of prospective cohort studies and randomized clinical trials on primary prevention of diabetes. They reported that a typical Western dietary pattern, rich in red and processed meats, refined grains, sugarsweetened beverages and desserts was associated with an increased risk for Type 2 diabetes. Physical activities were reported to have a significant inverse association with the development of diabetes. Daily walking for $>30$ minutes was associated with a $20 \%$ $45 \%$ risk reduction for diabetes. It was estimated that 30\% (95\% CI, 24\%-36\%) of new cases of obesity and $43 \%(95 \% \mathrm{CI}, 32 \%-52 \%)$ of new cases of diabetes could be prevented by adopting a relatively active lifestyle $(<10 \mathrm{hr} /$ wk of TV watching and $\geq 30$ min/day of brisk walking). The beneficial effects of smoking cessation on diabetes risk 
were found to outweigh the adverse effects on weight gain. Moderate alcohol consumption per day ( 2 ounces of hard liquor, or 10 ounces of wine, or 8-24 ounces of beer) was found to be consistently associated with lower incidence of diabetes. Heavy alcohol consumption per day ( $>2$ ounces of hard liquor, or 10 ounces of wine, or 8-24 ounces of beer) was associated with increased risk of developing diabetes.

Skyler (2004) conducted a review of randomized control trials that studied the effects of glycemic control on chronic diabetes complications. Tight glycemic control was found to reduce the risk of micro-vascular and neurological complications of diabetes. Early intervention was found to slow the progression of pre -Type 2 diabetes to a medical condition of diabetes. An intervention of diet or exercise resulted in $32-39 \%$ risk reduction for diabetes, whereas intervention with diet and exercise resulted in 58\% risk reduction for diabetes. Medication based interventions led to the following risk reductions: Metformin (31\%), Acarbose (32\%), Troglitazone (56\%), Xenica (45\%), and Troglitazone $(23 \%)$.

\section{Barriers to diabetes management}

A systematic review that summarized relevant cross-sectional studies, randomized control trials (RCTs), observational studies, and a qualitative study that addressed various perspectives and issues on the barriers to diabetes management was conducted by Nam, Chesla, Stotts, Kroon, \& Jason (2011). Articles from January 1990 through June 2009 were searched. A total of 80 studies that focused specifically on barriers to diabetes control or self-management among the Caucasians and the ethnic minorities were included. 
The systematic review discussed several patient factors that may contribute to barriers in diabetes management. Adherence, beliefs, attitudes, knowledge, language ability, financial resources, social support, and ethnicity/culture were identified. In terms of adherence, once-daily regimens were found to have higher rates of adherence than twice-daily regimens (61\% versus 52\%, respectively). Mono-therapy regimens were better than poly-therapy (49\% versus 36\%). Oral hypoglycemic agents' regimens were better than insulin ( $86 \%$ versus $73 \%$ ). Beliefs about the benefits of medications were also found to be strongly associated with adherence. Approximately $33 \%$ of patients were reported to be unwilling to take insulin if it were prescribed. Patients' reluctance in starting insulin therapy was reported to be associated with a perception that insulin therapy was evidence of personal failure, as well as a deserved punishment for failing to manage their disease. Fear of daily insulin injections was also reported.

The relationship between patients' knowledge and health outcomes was found to be inconsistent. Knowledge alone was reported not to be associated with adherence in the presence of other barriers. Language discordance between clinicians and patients was, however, reported to impact the process of patient education and adversely affected glycemic control.

Financial barriers and lack of health insurance were reported to be significantly associated with medications, non-adherence, and frequently missed medical appointments. Sixty percent of uninsured patients failed to obtain care following diagnosis compared with $6 \%$ of those who were insured. Lack of family support was reported to have a negative impact on diabetes self-management. Nam et al. (2011) did 
note that culture was a strong influence in an individual's beliefs, attitudes, knowledge, and behaviors, which in turn affected the management of their diabetes. Spiritualityfocused disease management was reported to be beneficial in providing diabetes care to African Americans as they usually turn to God for support during illness (Nam et al. (2011).

Studies that explore the barriers to diabetes management among African immigrants, particularly West African immigrants in the U.S. are very limited, and some are dated. In that context, literature related to barriers in West Africans, African Americans overall and African American immigrants, will be individually reviewed in this paper.

\title{
Factors Related to Barriers to Diabetes Management among West Africans in
}

\author{
Africa \\ Lack of knowledge, financial barriers, non-adherence to medication regimen, \\ cultural barriers such as self-medication with local herbs, and lack of privacy during \\ doctors' consultation were found to be related to poor diabetes management among Type \\ 2 diabetics in Nigeria (Yusuf, Obe, \& Joseph, 2007). Non-adherence to medication was \\ reported to be greatly associated with financial barriers, side effects of medications, and \\ perceived inefficiency of anti-diabetic drugs. Fifty percent of the 121 participants \\ reported non-adherence related to financial barriers and $34.5 \%$ of the participants \\ reported that their non-adherence to medications was related to side effects from the \\ medications.
}

Similar barriers to diabetes management were found in a study conducted among Cameroonians by Kiawi, Edwards, Shu, Unwin, \& Kamadjeu (2006). Lack of accurate 
knowledge of the diabetes disease process and management, nutritional habits, lack of facilities to exercise, inadequate time to exercise, cultural attachment to traditional management of diabetes, and socio-cultural barriers were found to contribute to poor outcomes of diabetes management. For instance, obesity, particularly in men was perceived as a sign of wealth. The study also revealed that some of the participants seek health care services only when in crisis.

Famuyiwa (1990) in review of the studies that explored the care of diabetic patients in Nigeria found that poor management of diabetes was associated with lack of knowledge by the patients, a culturally constructed concept of the disease, and ignorance on the part of other members of the community who are not diabetic. That author found that some patients turned to traditional healers who often made claims about their ability to cure diabetes. Cases of summary dismissals from jobs due to erroneous belief that diabetes is contagious and harassment of patients by the police for possession of insulin syringes and needles were reported.

Lack of accurate knowledge, cultural beliefs, and limited information about diabetes management from health care providers were also reported as barriers in a qualitative study conducted to explore the knowledge, attitudes and beliefs related to diabetes management among 142 patients in Nigeria by Famuyiwa, Edozien and Ukoli (1985). The authors reported that only $6 \%$ of the study participants had accurate knowledge about the causes of diabetes. According to Famuyiwa et al. (1985), 44\% of the participants indicated that they had no good knowledge and the rest mentioned a variety of causes of diabetes such as 'evil-doers' or 'bad blood'. Twenty-three percent 
had the belief that diabetes was curable and some believed it was contagious. Only $19.3 \%$ reported getting detailed information about diabetes management from healthcare providers, while $37.8 \%$ said they were not provided any information, and $42.8 \%$ said they heard 'something about sugar'. Some of the patients resorted to "witchcraft" (the use of spells and invocation of evil spirits) in search of a diabetes cure because of the perception that the disease was caused by evil-doers.

\section{Factors Related to Barriers to Diabetes Management among African American Population}

A study conducted to explore the facilitators and barriers to self-management of diabetes among 38 urban African American adults revealed the following barriers: pain associated with glucose monitoring, nutritional habits, memory failure, and perceived lack of personal control over diabetes (Chlebowy, Hood, \& LaJoie, 2010). That study also indicated when health care providers were available to the patients they positively influenced adherence behaviors by providing cues to action, direct assistance, reinforcement, and knowledge. However, Chlebowy et al. (2010) discovered that few of the study participants did not have primary care physician and the most common deciding factor for a clinic or a hospital visit was need for emergency health care.

Similarly represented are studies that direct attention to barriers to diabetes management among rural dwelling African American diabetes patients. For example, in a study that explored the barriers to diabetes self-management among this population, Utz, Steeves, Wenzel, Hinton, Jones, Andrews, Murphy, and Oliver (2006) found the following barriers: lack of knowledge, cost of medications and supplies, complexity of 
diabetes management regimen, fitting the complex regimen into daily demands to achieve good quality of life, difficulty managing appetite, and stigma of diabetes. Contrary to the urban American population, this group reported difficulties in finding diabetes specialists. This negatively influenced adherence behaviors.

\section{Factors Related to Barriers to Diabetes Management among African Immigrants in}

\section{the U.S.}

Little research has been conducted to explore the barriers to diabetes management that West African immigrants encounter in the course of their everyday lives in the U.S. Given the increasing growth of the West African population in the U.S. and the incidence and prevalence of the disease among this population, these phenomena must be explored.

McGuigan (2010) conducted a qualitative study to explore the unique cultural factors that impacted diabetes self-management in the Eritrean and Ethiopian (East African) immigrant communities of Seattle, Washington. Interviews with 40 crossgenerational members of the community who had resided in the U.S. for five years revealed the following barriers: denial of disease diagnosis, difficulties with diet management, lack of accurate knowledge about diabetes management, health culture, religion and spiritual beliefs that prevented the receiving of treatment, language barriers, financial difficulties, lack of health insurance, difficulties navigating the health care systems, barriers to physical activities, and medication non-adherence due to financial reasons, fear of side effects, and fear of addiction. Denial of having the disease was among the common themes; for example, one patient stated, "I have been living healthy for over 60 years, how could I be diabetic? I don't feel sick." Another common theme 
was diet management; the Eritreans and Ethiopians continue to adhere to traditional eating habits. They have access to traditional high calorie foods through the specialty African stores and continue to eat traditional foods prepared at home. Eating large portions of food is regarded as a sign of good health. The Eritrean health care culture was a common barrier; prevention and chronic disease management were regarded as foreign concepts. Many of the participants reported that health care is a luxury back home and therefore they go to the clinic only when they are sick. Further, they expect a short course of medication that 'cures' the problem rather than a long-term medication regimen. The Eritreans' religion and spiritual beliefs were other prevailing barriers to health management among the participants; holy water and prayers still remained a powerful healing force for many general illnesses in these communities. Medication non-adherence was important and commonly identified; some participants reported fear of side effects as the cause of non-adherence while some perceived long-term medication adherence as addiction rather than chronic disease management. Medication non-adherence was reported to be associated with problems of medication refills; some participants felt that once the bottle is empty the treatment is done, and others waited for their next visit before they obtained another refill. A barrier to physical activities was also a common theme. This was related to cold weather, busy work schedules, and a fear of walking alone due to not feeling safe in the neighborhood.

A similar study was conducted to investigate how the French-speaking West Africans from Senegal and the Republic of Guinea manage their Type 2 diabetes in the U.S. (Ndiaye, 2009). The following research questions were addressed in the study: 
"How do they gather information on diabetes? What sources of information do they use? How do they transform that information into knowledge? What is the impact of literacy in their diabetes management? How much of an effect if any do the beliefs about health play in their diabetes care?" (Ndiaye, 2009, p.16). The study revealed that the main sources of diabetes information for most of the participants were: the internet, the radio, television programs, magazines/articles, and anecdotal information from friends and family. They received limited information from health care providers. Other barriers identified include financial difficulties and lack of health insurance. As reported by that author, patients without health insurance could not afford to pay the out of pocket cost for medications. Nutrition and difficulties with food portions were barriers. Rice is the staple food in Senegal; it is eaten at least once a day regardless of health concerns. Within a family group, no meal was tailor-made for just one person, mostly because of the lack of means. Language barriers were identified as an issue. The author noted that all participants could read, write, and understand the English language to varying degrees. The main problem was the spoken words; participants had difficulties communicating fluently and being clearly understood. Religion and spirituality were found as impediments to care seeking compliance when assistance was given; most of the participants believed that God controls their health and that 'He' has the final word on whether they stay healthy or not.

\section{Summary of Key Literature}

Diabetes is a serious disease that can lead to debilitating health complications and even death. Early prevention and management are essential. Review of relevant literature 
revealed that, in the U.S., racial and ethnic minorities with diabetes are more likely to develop complications and often experience premature morbidity and mortality. Immigrants, including West African immigrants, are particularly vulnerable. This literature review revealed possible hypotheses to explain the occurrence of diabetes complications, morbidity, and premature mortality. They include insufficient diabetes education, lack of an accurate knowledge base about diabetes disease management, cultural and financial barriers to the access of health care, culturally constructed concepts of the disease, habitual eating of a high carbohydrate diet, religious beliefs and values, barriers to physical activities, language barriers between patient and provider, and medication non-adherence for a variety of reasons. As the West African immigrant population continues to grow in the U.S., more research is necessary to understand their lived experiences and the barriers they face in the management of chronic diseases, especially diabetes. Understanding these barriers is paramount, and is the first step to providing culturally competent diabetes care to this population. The purpose of this study was to explore the barriers to diabetes management among West African immigrants living in Rhode Island. 


\section{Study Design and Methods}

This study is a qualitative research project designed to explore the barriers West African immigrants (Nigerian, Liberian, and Ghanaian) living in Rhode Island, ages 18 years and older with Type 1 or Type 2 diabetes encounter with diabetes management. Demographic data was collected using a questionnaire (Appendix A). This provided the researcher with background information of the participants. Then one-on-one, face-toface, semi-structured interviews with participants explored the beliefs, practices, and other factors that each respondent said affected his/her diabetes management. An Interview Guide of open-ended questions (Appendix B) guided this phase of the data collection. This Guide had been previously reviewed by members of the West African immigrant community for clarity and focus of the questions.

\section{Sample}

Prior to recruitment, approval of the study for the protection of human subjects was obtained from the Rhode Island College Institutional Review Board, and a permission from the African Alliance of Rhode Island to recruit participants was received. A convenience sample of five adults $(\mathrm{N}=5)$; men $(\mathrm{n}=2)$, women $(\mathrm{n}=3)$, Nigerian $(\mathrm{n}=3)$, Liberian $(\mathrm{n}=1)$, and Ghanaian $(\mathrm{n}=1)$ was established through a community flyer advertisement.

All volunteers met the study criteria for inclusion as immigrants from West Africa, diagnosed with Type 2 diabetes, over 18 years of age, and able to understand, read, and speak English. In addition, all agreed to participate in the audio-taped one-on-one interview and were capable of giving informed consent. 


\section{Procedure}

The questionnaire used to collect demographic information and the Interview Guide were developed by the researcher specifically for this study to explore the barriers to diabetes management among West African immigrants living in Rhode Island. All interviews were scheduled when and where convenient for the participants and by the researcher in either the participant's home or at the African Alliance of Rhode Island's Providence location. Informed consent (Appendix C) was obtained before starting each interview. All participants were assured of confidentiality. Each interview was conducted in a quiet room with adequate interview space. Participants were told that they had the right to withdraw at any time or refuse to answer any question without reprisal. As the participants shared specific experiences, additional probing questions were used as necessary to gain a more in-depth understanding or to clarify information. All interviews were audio-taped, and lasted approximately 50 minutes. Field notes were made by the researcher immediately after each interview was completed. In addition, a reflective diary was kept by the researcher.

\section{Data Analysis}

The tape-recorded conversations were transcribed verbatim by a clerk. Each transcript was then read by the researcher and carefully compared with the audio recording. Interview transcripts were then imported and encoded into QRS International's NVivo 10. This was done by a contracted QRS NVivo specialist in order to ensure the validity and reliability of coding schemes. NVivo 10 has been used in various qualitative studies; it allows for consistent coding schemes and provides the tools to query and audit 
the coding processes, thereby producing more robust interpretations of data (Bergin, 2011). Utilizing the NVivo program, sub-codes or "analytic variables" emerged as well as "free nodes" for that data which did not readily categorize or fit into the existing groups or categories. Miles and Huberman's (1994) three major approaches to content analysis were followed.

The process of first-level coding [or data reduction] wherein a line-by-line analysis which highlighted chunks of varying size, for example, phrases, sentences, or whole paragraphs were pasted into to particular analytic categories. Thus several paragraphs of text were reduced through content coding. As new meanings or categories emerged, codes were added or modified (Schilling, 2006).

The process of second-level coding is the more detailed indexing. Concepts were further explored and indexed according to content that facilitated the development of visual index trees and their subsequent concept formation comprising sub-categories or branch nodes for the whole project. Codes were rechecked and assigned text to assess coding consistency (Miles \& Huberman, 1994; Weber, 1990).

The third and final process was the continual checking and comparing of emerging codes with most sources and frequencies for differences and similarities using a constant comparative method described by Glaser and Strauss (1967). Each piece of text was systematically compared and assigned to themes. Each theme was presented using a table. In order to substantiate derived themes, each theme was supported by a rich description of texts and direct quotations from the participants themselves. The 
statements that formed the themes were grouped and combined to form paragraphs that formulated the results of the study (Locke et al., 2000).

\section{Results}

There were five participants, two males and three females. As illustrated on Table 2.0, three of the five participants were from Nigeria, one was from Liberia, and one was from Ghana. Four of the participants fell into 51-60 year old range with one participant in 41-50 year old range. All participants identified themselves as following Christian beliefs. Three participants attained and reached the tertiary level education (college graduates), one reached the secondary level (high school graduate), while one had no formal education. Four were employed. All had health insurance and had been diagnosed with Type 2 diabetes. Only one identified a health problem (poor eyesight) that may be related to the medical diagnosis of Type 2 diabetes.

\section{Table 2.0}

\section{Demographic characteristics of study participants $(N=5)$}

\begin{tabular}{|c|c|c|c|c|c|c|c|c|c|c|c|c|}
\hline $\begin{array}{l}\text { Participant's } \\
\text { Country of } \\
\text { Birth }\end{array}$ & Age & Gender & Religion & $\begin{array}{c}\text { Educational } \\
\text { Level }\end{array}$ & $\begin{array}{c}\text { Employment } \\
\text { Status }\end{array}$ & $\begin{array}{c}\text { Year of } \\
\text { Migration } \\
\text { in the } \\
\text { U.S. }\end{array}$ & $\begin{array}{c}\text { Health } \\
\text { Insurance }\end{array}$ & $\begin{array}{c}\text { Years } \\
\text { of being } \\
\text { a } \\
\text { Diabetic }\end{array}$ & $\begin{array}{l}\text { Family } \\
\text { History }\end{array}$ & Complication & $\begin{array}{l}\text { Last } \\
\text { Check- } \\
\text { Up }\end{array}$ & $\begin{array}{l}\text { Type of } \\
\text { Diabetes }\end{array}$ \\
\hline $\begin{array}{c}\text { Participant \# } \\
1 \\
\text { Nigeria }\end{array}$ & $\begin{array}{c}51-60 \\
\text { years } \\
\text { old }\end{array}$ & Male & Christian & $\begin{array}{l}\text { Tertiary } \\
\text { Level }\end{array}$ & Employed & 2000 & Yes & 6 years & None & Eyesight & $\begin{array}{c}\text { December } \\
2012\end{array}$ & Type II \\
\hline $\begin{array}{c}\text { Participant \# } \\
2 \\
\text { Liberia }\end{array}$ & $\begin{array}{c}51-60 \\
\text { years } \\
\text { old }\end{array}$ & Female & Christian & $\begin{array}{l}\text { No formal } \\
\text { education }\end{array}$ & Unemployed & 2006 & Yes & 5 years & None & None & $\begin{array}{c}\text { February } \\
2013\end{array}$ & Type II \\
\hline $\begin{array}{c}\text { Participant \# } \\
3 \\
\text { Ghana }\end{array}$ & $\begin{array}{c}41-50 \\
\text { years } \\
\text { old }\end{array}$ & Female & Christian & $\begin{array}{l}\text { Secondary } \\
\text { Level }\end{array}$ & Employed & 1991 & Yes & 9 years & Yes & None & $\begin{array}{c}\text { November } \\
2012\end{array}$ & Type II \\
\hline $\begin{array}{c}\text { Participant \# } \\
4 \\
\text { Nigeria }\end{array}$ & $\begin{array}{c}51-60 \\
\text { years } \\
\text { old }\end{array}$ & Male & Christian & $\begin{array}{l}\text { Tertiary } \\
\text { Level }\end{array}$ & Employed & 1991 & Yes & $\begin{array}{c}1-5 \\
\text { years }\end{array}$ & Yes & None & $\begin{array}{c}\text { February } \\
2013\end{array}$ & Type II \\
\hline $\begin{array}{c}\text { Participant \# } \\
5 \\
\text { Nigeria }\end{array}$ & $\begin{array}{c}51-60 \\
\text { years } \\
\text { old }\end{array}$ & Female & Christian & $\begin{array}{l}\text { Tertiary } \\
\text { Level }\end{array}$ & Employed & 1981 & Yes & 15 years & Yes & None & $\begin{array}{c}\text { December } \\
2012\end{array}$ & Type II \\
\hline
\end{tabular}


The findings of the study revealed eight main themes of participants' barriers to diabetes management. They are illustrated in Table 3.0

Table 3.0

Participants' Barriers to Diabetes Management

\begin{tabular}{|c|c|c|}
\hline Barrier to Diabetes Management & Number of Respondents & $\begin{array}{l}\text { Number of } \\
\text { Respondents in } \\
\text { Percentage }\end{array}$ \\
\hline Dietary Habits & 4 & $80 \%$ \\
\hline Financial Difficulties & 4 & $80 \%$ \\
\hline $\begin{array}{l}\text { Taking Care of Diabetes } \\
\text { (Non-adherence to daily maintenance) } \\
\text { Cultural Attachment to Traditional } \\
\text { Management }\end{array}$ & 3 & $\begin{array}{l}60 \% \\
60 \%\end{array}$ \\
\hline $\begin{array}{l}\text { Cultural Beliefs and Habits } \\
\text { (Lack of belief in taking good care of } \\
\text { your health) }\end{array}$ & 3 & $60 \%$ \\
\hline $\begin{array}{l}\text { Negative Relationship with Primary } \\
\text { Doctor }\end{array}$ & 2 & $40 \%$ \\
\hline $\begin{array}{l}\text { Non-adherence to the Prescribed } \\
\text { Medications }\end{array}$ & 1 & $20 \%$ \\
\hline $\begin{array}{l}\text { Practitioners' inadequate knowledge } \\
\text { of cultural care }\end{array}$ & 3 & $60 \%$ \\
\hline
\end{tabular}


Direct quote statements from the participants that formed the themes are illustrated in

Table 3.1-3.8. The symbol [ ] indicates a clarification statement by the researcher, while “ " indicates a participant's response.

\section{Table 3.1}

The First Barrier to Diabetes Management: Dietary Habits

Barrier to Diabetes Management:

Dietary Habits $(n=4)$
Participant 2 (Female, Liberia): "Sometime I want to eat my African food. I eat it once awhile... like - the way I used to eat before, I can't eat like that... The problem to me- the problem is that, to me, we all-eat white rice. We eat all kind of starchy food. We eat cassava, all kind of starch food... We eat it with sugar; we eat sugar, a lot of sugar."

Participant 3 (Female, Ghana): "Okay. The only thing is that with the African food, I don't know how to regulate and I don't know how to portion. The only thing, if-let's say, if I eat African Food, like cassava, rice, if I eat it, my sugar goes really high... The African food, I don't know how to portion it at all. I sometimes leave it alone."

Participant 4 (Male, Nigeria): "I mean back home I eat carbs in the morning, I eat carbs too in the afternoon. They eat carbs at night too. Nobody bothered about sugar. [How to count carbohydrates?] It was a little complicated."

Participant 5 (Female, Nigeria): “... Mostly all our food is carbohydrate---so we eat it every day...eating it at night. It is bad. I don't know about the type of food we can eat." 


\section{Table 3.2}

The Second Barrier to Diabetes Management: Financial Difficulties

Barrier to Diabetes Management:

Financial Difficulties $(n=4)$
Participant 1 (Male, Nigeria): "The Dietician spoke to me about the diet in short, I tried, but I couldn't. It was difficult to maintain. If somebody were to maintain that, apart from that, from the difficulties, it's expensive to be on a diet. Certain foods, one portion, this portion, that portion. It's a lot."

Participant 2 (Female, Liberia): [You mean getting the recommended juices and drinks?] "It was a little bit expensive more than the regular cranberry juice. Yes. It's a big problem for me to get it sometimes because of the cost. I can't able to get it. The food is expensive, very expensive."

Participant 3 (Female, Ghana): “...Once it ran out, I have to wait for a month, and there's nothing. We can't have insulin refill if it runs out" [you can't purchase it? or] "Yes. Based on the insurance... Yes, I can get it if I have the money." [So the money is an issue then. Are they very expensive?] "Yes, it's $\$ 150$ a bottle and I have to buy two, which is $\$ 300$."

Participant 5 (Female, Nigeria): "[Green vegetables diet as suggested by the dietician?] "I think so, yeah. They are more expensive now, but hey, I got to eat, so - It's kind of hard, but it's okay. It's okay, yeah." [So managing to get them becomes an issue] "Sometimes, yes." 
Table 3.3

The Third Barrier to Diabetes Management: Taking Care of Diabetes or the Non-adherence to daily maintenance

Barrier to Diabetes Management:

Participant 3 (Female, Ghana): [Saying that your need to exercise three times a week, at least

Taking Care of Diabetes or the Non-adherence to make it work, may be 30 minutes every day, five days a week is a problem?]. "Unfortunately, to daily maintenance) $(n=3)$ work. My work schedule and the same time, the kids. It's not easy."

Participant 4 (Male, Nigeria): "I'm hoping to find a better way to test the sugar because the pricking once every day. I don't do mine every day. [Because of the pain?] "Oh, yes. Oh, yes. I don't do it every day. I do it maybe every two or three days."

Participant 5 (Female, Nigeria): "Well, checking my sugar is not convenient. Like me, I check twice, at least once a day. Before I was checking three times a day, now I change it to once because all my fingers are all-yeah, that's the only difficult thing that I can think of right now."

\section{Table 3.4}

\section{The Fourth Barrier to Diabetes Management: Cultural Attachment to Traditional}

\section{Management}

Barrier to Diabetes Management:

\section{Cultural Attachment to Traditional}

Management $(n=3)$
Participant 1 (Male, Nigeria): “... In short, there was a time that I feel dizzy here and I say, okay. I wanted to have a "niti" concoction back in Africa. That is a traditional... medicine. I sent my wife to one of the stores to buy those things."

Participant 3 (Female, Ghana): “Actually, every time I go back home to Ghana, I do the herbal medicine." [Which is?]_- "yes, which is mango tree. I just boil it and then blend it and then squeeze the water out. When I drink that, I don't have to take the shots or anything. It works for me and I bring some here to U.S." 
Participant 4: (Male, Nigeria): "At one time, I said, "This medication is synthetic so I'm going to try the apple cider vinegar." Just to prove a point to myself, I didn't take the medication for a long time, but I would do apple cider vinegar, and my sugar then was 6.8. I said, "Well, if this comes down without using the medication for one or two points, then something good is happening." I went to the doctor again and did the test, and they told me, "Oh, yeah. You are getting better."

Note: A popular name for "niti" concoction is "agbo" in Nigeria.

Table 3.5

The Fifth Barrier to Diabetes Management: Cultural Beliefs and Habits (Lack of belief in taking good care of their health)

Barrier to Diabetes Management:

Cultural Beliefs and Habits (Lack of belief in

taking good care of their health) $(n=3)$
Participant 1 (Male, Nigeria): "Because most of us are in Africa, we don't believe that we need constant checking, especially men. We say I'm okay, I'm okay, I'm okay. We need constant checking. Check, go to the doctor, check. I don't find it necessary if I m not sick"

Participant 4 (Male, Nigeria): "Africans have the attitude of waiting for complications before taking action" [Africans, generally?] "Yes" [they take a lot of things like that for granted?] "Yes. It's like knowing something might eventually get you, and you say, well, for now, I'm okay. Everything's alright. Then, until one day, you wake up in the morning and you feel some strange tingling in the left leg somewhere. Then, you go to the doctor... What I've been saying all along is the willingness to do something about it at the initial level is lacking. I do that a lot."

Participant 5 (Female, Nigeria): "It's our habit. We don't care about checking our health in our culture. Except we are sick, that's when you go to the doctor. If you are not sick, you don't go to the doctor. If you are not sick over here, they still want you to check yourself out at least once in three months. We from Africa, we are not used to that" 
Table 3.6

The Sixth Barrier to Diabetes Management: Negative Relationship with Primary Doctor

Barrier to Diabetes Management:

Participant 3 (Female, Ghana): "[Relationship with the doctor is...] "Not much. No, not really...

Negative Relationship with Primary Doctor I found out by myself, you know I was trying to get pregnant. I'm not supposed to take the $(\mathbf{n}=\mathbf{2})$ Metformin because if you take it, you won't be able to get pregnant. She said yeah, and then she just put me on the insulin... Oh, I was really upset. I had to change her right away because I wasn't comfortable with her. Yeah, she just didn't seem to have time for me at all."

Participant 5 (Female, Nigeria): "Limited information from the doctor. All the food that I eat when I take my insulin, it shoot my glucose up. I actually limit eating it. None of those the doctor tell me. The doctor did not tell me the kind of food to eat"

\section{Table 3.7}

The Seventh Barrier to Diabetes Management: Non-adherence to the Prescribed Medications

Barrier to Diabetes Management:

Non-adherence to prescribed

Medications ( $\mathrm{n}=1)$
Participant 4 (Male, Nigeria): [Have you been taking your medications faithfully?] "Not very. Medications can be very difficult for me to take-well, this is about me. Well, the situation is sometimes, I leave the house. I don't eat. I am not going to take it until I eat." 
Table 3.8

The eighth Barrier to Diabetes Management: Practitioners' inadequate knowledge of cultural care

Barrier to Diabetes Management:

Practitioners' inadequate knowledge of

cultural care (No culturally sensitive

education on diet management $)(n=3)$
Participant 1 (Male, Nigeria): [Did your

doctor understand your culture pertinent to your food, or how was he able to guide you in regulating your diet?] "He did not fully understand African food. He said try this and let me see you after a week."

Participant 3 (Female, Ghanaian): [Did your provider help you figure out how to eat healthy in your own culture?] "Not really. He doesn't know much about that. He doesn't know anything about African food. The only thing is that with African food, I don't know how to regulate and I don't know how to portion. Once a while, when I feel like it, I eat it and I double my insulin because my sugar usually goes up when I eat food like cassava or rice. The only advice my provider gave me was to leave the African food alone and then concentrate on the vegetables and all the American food in America."

Participant 4 (Male, Nigeria): [Is it a problem understanding or interpreting the portion or the calorie counts in African food or what?] "Reading the pamphlet given to me on diet by my dietician, I think-I'm unable to understand the choices and how to quantify-I mean the quantity of carbohydrates that I can take. It was a little complicated. I had to take two carbs-I mean two parts of carbs, and then I start wondering, what do I count here. There is no clear direction on how to count calories with African food." 


\section{Discussion}

In this study, a small sample of West African immigrants from Ghana, Liberia, and Nigeria diagnosed with diabetes, now living in Rhode Island were interviewed about barriers they have experienced related to their diabetes management. Participants who met the criteria volunteered to discuss their beliefs, practices, knowledge, experiences, and other factors that affected their ability to manage their diabetes. After the completion of the interpretative analysis process, eight pertinent themes emerged.

The ages of the five respondents range from 41 to 60 years old. All respondents had been diagnosed with Type 2 Diabetes Mellitus (DM). Since Type 2 diabetes accounts for 90-95\% of those diagnosed with DM and is often associated with older age (CDC, 2011), this was not surprising.

The number of years since participants had been diagnosed with diabetes ranged from 1-15 years. Two of the five respondents had no family background or history of diabetes. Only one participant stated that they have a complication that may be a result of their diabetes.

Published studies have revealed that "lack of health insurance" and the "non-use of primary care physician" were common barriers reported by West African Immigrants and African Americans in the U.S. (McGuigan, 2010; Chlebowy, Hood, \& LaJoie, 2010). Conversely, all of the participants in this study had health insurance and each stated that they had visited their primary doctors since being diagnosed with diabetes.

Participants in this study shared that they had found a variety of barriers. Four of the five stated that dietary habits were the most important barrier that needed to be addressed. 
Their lack of understanding on how to properly portion their food hindered the management of their health condition. They also reported that the dietary recommendations made by their health care providers were not consistent with the traditional West African foods they prefer to eat. These participants stated that they were uncertain about the appropriate portion sizes. They also reported that they frequently ate traditional African foods with high carbohydrate content like cassava and rice. For these four participants, modifying their diets was the most challenging aspect about self-care of Type 2 diabetes.

The finding that these study participants struggled to modify their traditional West African diet is consistent with the results of a study McGuigan, (2010) conducted with Eritrean and Ethiopian immigrants and another by Ndiaye, (2009) with French-speaking West African immigrants from Senegal and the Republic of Guinea. The respondents in those studies reported that they have access to traditional high calorie foods through the specialty African stores and continue to eat traditional food prepared at home. They also reported a difficulty with choosing appropriate food portions.

Three of the participants $(60 \%)$ reported that the problem was the "practitioner's inadequate knowledge of cultural care specifically related to dietary management." The health care practitioners and dieticians were unfamiliar with the traditional West African diet so they often recommended traditional American foods; however, they are not an acceptable option. Dietary guidelines for this population must be prepared to assist health care practitioners who treat immigrants in the U.S. from West African communities. In order to effectively manage this population's Type 2 diabetes, providers must have 
knowledge of the nutritional values of traditional foods and dishes, appropriate and acceptable substitutions for high carbohydrate foods, and an estimation of appropriate portion sizes.

Food has a specific value and significance among different minority ethnic groups but if people are aware of healthier options, they may be willing to adjust the amount and selection of what they eat without abandoning their ethnic foods (Venelda-Carr, C. 2012). This concept relates to the theoretical framework used for this study: "Madeleine Leininger's Cultural Care Diversity and Universality.” One of Leininger's proposed models for nursing decision-making and subsequent actions is "cultural care preservation." Cultural care preservation refers to nursing actions that safeguard cultural practices of the patient while also helping to maintain good health (Leininger, 1988). This relates to gaining both an understanding of what the diagnosis means to a patient with diabetes and how the patient can continue to eat traditional foods without a negative impact on blood glucose levels. Clinicians must become aware of the ways they could make their dietary advice more effective for minority ethnic groups (Venelda- Carr, 2012).

Financial difficulties have been reported by other researchers as a recurring barrier to diabetes management among minority populations in the U.S., and among West Africans in Africa (Nam et al, 2011; McGuigan, 2010; Ndiaye, 2009; Yusuf, Obe, \& Joseph, 2007). This was also a finding of this research. Four study participants (80\%) reported financial difficulties as a barrier. They expressed concerns that the high financial costs that come with their sickness are impacting their diabetes management negatively. 
The participants reported that once their insulin for the month runs out they are forced to wait until their insurance coverage will pay for them again or they must pay out of pocket, which oftentimes is too expensive for them to afford.

In terms of their diet, participants stated that the recommended fruits and vegetables are expensive, and that oftentimes they are unable to follow the recommended diet. Instead, they fall back on their traditional foods like cassava, rice, and yam which are less expensive. With these financial constraints, the respondents had difficulties meeting the expectations of care for their illness and, as a result, are at higher risk for diabetes complications and poor outcomes.

This study also revealed that three participants $(60 \%)$ experienced several other barriers to recommended daily diabetes maintenance or management. One participant reported difficulties in adding the needed exercise and workout to her daily schedule of work and childcare. Two of the participants reported pain associated with pricking of fingers for blood sugar checks as a problem. As a result, each had decreased the frequency of checking their blood sugar contrary to what was recommended by their health care providers. These findings are consistent with findings of the study by Utz, Steeves, Wenzel, Hinton, Jones, Andrews, Murphy, \& Oliver (2006) in which African Americans with diabetes complained about the complexity of diabetes management regimen and difficulties encountered when fitting the complex regimen into their daily routine. A similar study with Eritrean and Ethiopian immigrants also revealed barriers to physical activities. The Eritreans related decreased compliance to physical exercise to cold weather, busy work schedules, and a fear of walking alone (McGuigan, 2010). One 
of the roles of the APRN is to teach and encourage patients about the behavioral changes that could have a positive impact on their health. However, the development of the plan must be in collaboration with the patient. Following Leningers' model of 'cultural care re-patterning,' the provider works with the patient to adapt their patterns of behavior in a way that promotes health.

The cultural beliefs and habits of three of the participants $(60 \%)$ in this study, particularly their lack of belief in the importance of taking care of their health, had a negative effect on their ability to effectively manage Type 2 diabetes. One of the participants elaborated on this barrier and explained why it is a hindrance to diabetes management, not only for himself but to the whole African community. He explained, "Africans have the attitude of waiting for complications before taking action. Africans, generally... take a lot of things like that for granted." One participant also explained that most Africans do not believe in regular health checks. Such attitudes were also echoed by another participant who stated, "we don't care about checking our health in our culture, except when we are sick, that's when we go to the doctor." These findings were aligned with the study that showed the same belief among West Africans living in Africa and the Eritrean and Ethiopian immigrants in the U.S. (Kiawi, Edwards, Shu, Unwin, \& Kamadjeu 2006; McGuigan, 2010). The participants in those studies held a belief that they needed to seek health care services only when they were sick or when in crisis. Finding a balance between their beliefs and the western model of preventative care practices is central to their ability to effectively maintain and engage in healthy 
behaviors. This conflict presents an excellent opportunity for the APRN to educate this population about preventive health behaviors.

Three respondents $(60 \%)$ believed in the use of traditional/ herbal medicine. The use of culturally supported remedies and/or herbal medicine is very common among West Africans. It is estimated that between $70-80 \%$ of West Africans use traditional medicine for the management of both communicable and non-communicable diseases (World Health Organization, 2010). The participants in this study reported that the traditional remedies being used for Type 2 diabetes were herbal concoctions called "Niti," "Mango tree," and "Apple cider vinegar." Unfortunately, the lack of pharmacologic evidence and the hypoglycemic risk of some herbal remedies create a challenge for health care providers (WHO, 2001; Ernst E, 2002; Gardiner, Phillips, \& Shaughnessy, 2008).

The use of traditional remedies by participants in this study conflicted with the use of the western medicines for treatment of Type 2 diabetes. Study participants claimed to obtain good outcomes from using traditional remedies and combined herbal medications with the western medications prescribed by their health care providers or they just used the herbal medicine alone. Combination of the herbal medicines with oral diabetes medicine or insulin could result in a hypoglycemic crisis (WHO, 2001). The practitioner's assessment of medication history, specifically asking about complimentary/alternative medicines, is crucial for successful modification of treatment strategies and subsequent outcome evaluations.

Two study participants $(40 \%)$ reported that they had a negative relationship with their primary care doctors; for instance, one participant reported receiving limited 
information and another participant reported that her health care provider was not receptive to her complaints. The participants' negative experiences led them to withdraw from the physicians. Therefore, they were unable to build a relationship that would be beneficial for both parties. To appropriately assist patients with their self-management behaviors, health care providers must cultivate patient-centered relationships that respect the patient's personal and cultural autonomy; organize the environment to be patientfriendly; provide continuity of care with interim contacts to the patient; and communicate collaboratively with each patient about their individual treatment goals and rationales (Delamater, 2006).

The barrier that was identified by only one respondent $(20 \%)$ was the non-adherence to prescribed medications. Participant reported frequently missed medication. Medication adherence is a growing concern to clinicians, healthcare systems, and insurance companies because of mounting evidence that non-adherence is prevalent and associated with adverse outcomes and higher cost of care (Osterberg \& Blaschke, 2005). In this study, the patient reported that his schedule often led to forgetting to take the prescribed medications. Care providers and patients can work collaboratively to develop patientspecific solutions to address such an adherence barrier. Evidence-based interventions that have demonstrated success include reducing the number of daily doses of medications, organizing medications in a pill box, encouraging the patient using motivational interviewing, and educating the patient on the long-term importance of medication adherence (Michael, Bryson, \& Rumsfeld, 2009). 
This study utilized a small sample size because of a limited time for the research. However, the participants were good informants and were able to discuss their experiences and communicate effectively, therefore data saturation was achieved. In qualitative research, the main criterion for sample size adequacy is data saturation (Polit \& Beck, 2006).

Sample selection: This study used a convenience sample of Nigerians, Ghanaians, and Liberians. Therefore the study sample was not representative of the entire West African immigrant population represented in the U.S.

Respondents' bias: Knowing the focus of the interview, the self-selection of volunteers for the study and subsequent response biases might have occurred with subjects. The potential response bias in an open-ended interview, relying solely on exploratory openended questions, limits the generalization of results (Tong, Sainsbury \& Craig, 2007). 


\section{Conclusions}

The findings in this study supported that cultural and non-cultural barriers to diabetes management exist among this sample of West African immigrants living in RI. The findings also provide valuable insight into the barriers and challenges that come with their management of Type 2 diabetes and provide an opportunity to educate health professionals about the importance of providing culturally congruent care. Prior studies that explored these barriers are limited. Yet understanding and addressing the barriers are paramount to the health and well-being of these patients. If these barriers are not explored, this culturally diverse population will continue to be at risk for diabetes complications, increased morbidity, and premature mortality. The findings in this study support the necessity of further exploration of the need for culturally congruent interventions to improve diabetes outcomes among West African immigrants living in RI and across the U.S.

\section{Recommendations and Implications}

While the study sample was not representative of the entire West African immigrant population in the U.S., these findings have important implications for the organization and delivery of diabetes prevention and management strategies in this community and in other minority groups.

The reality presented from this study shows that health care providers must be committed to the greater good of the West African immigrants diagnosed with diabetes and not harm them by our ignorance and rejection of cultural beliefs. It is time for the delivery of more culturally sensitive and culturally tailored health programs for the 
management of diabetes within this population. Health service delivery policies and strategies need to recognize the unique needs and barriers facing this specific immigrant population.

Diabetes management is significantly influenced by demographics, psychosocial factors, and lay beliefs. It is consequently necessary to understand patients in their social and cultural context and to acknowledge their individual beliefs (Schoenberg, Amey, \& Coward, 1998).

Community information sharing networks and community based informal and formal support systems should be considered as the foundation for diabetes prevention education and health promotion strategies (National Diabetes Education Programs [NDEP], 2009). Culturally appropriate health education efforts should utilize all available means such as community groups, religious forums, and intra-cultural media to reach out to this population regarding diabetes prevention, management, and care.

Each APRN must address patient education on a regular basis, not just at diagnosis. Education should explain how dietary management is central to effective Type 2 diabetes care. A collaboration of health practitioners, dieticians, and West African community associations is needed to develop a health promotion and awareness strategy, support healthy diets, and encourage physical activity among members of this community with Type 2 diabetes.

Nutrition educational programs should be created based on recommendations from the American Diabetes Association and adapted to meet the dietary needs of the West African community. With the guidance of dieticians, cooking classes can be arranged at 
community events and at religion centers. These classes would instruct those responsible for preparing the food for families on how to prepare healthier traditional West African dishes, as well as how to measure portion sizes. Participants would be provided with nutritional information materials so they may determine the calorie content of traditionally eaten West African foods and encouraged to use kitchen scales to measure ingredients and portion sizes.

All patients, including patients from other ethnic groups, must be asked about all medications that they take, including the use of any complementary or alternative mode of therapy. The toxic and hypoglycemic affect of most herbal remedies for diabetes make this aspect of the patients' beliefs and behaviors an imperative at every encounter with a patient diagnosed with diabetes (Mbaya, 2010). However, knowing that a provider may not approve, accurate responses may not be provided. More research is needed to determine how the patients' disclosure of use of complementary or alternative medicine can be improved and positively affect patient-provider interactions.

There is a need for more scholarly nursing inquiries to provide a better understanding of the barriers faced by minority groups in the U.S including West African immigrants in order to promote healthy diabetes management and target interventions that improve diabetes outcomes in this high risk population. 


\section{References}

Abubakari, A.R., Lauder, W., Jones, M.C., Kirk, A., Agyemang, C., \& Bhopal, R.S. (2009). Prevalence and Time Trend in, Physical Inactivity and Diabetes in Adult West African Populations: The epidemic has arrived. Public Health. 123, 602-614.

African American Community Health Advisory Committee (2009). African Americans and Diabetes. Health and Fact Sheets. Retrieved from: http://www.aachac.org/healthfactsheets/diabetes.html.

Archibald, C. (2011). Cultural Tailoring for an Afro-Caribbean Community: A naturalistic approach. Journal of Cultural Diversity. 18(4), 114-119.

Batts-Tutner, M.L. (2007). Fighting Diabetes Disparities in Communities of Color. Career and Educational Resource for Minority Nurse. Retrieved from: http://www.minoritynurse.com.

Bergin, M. (2011). NVivo 8 and Consistency in Data Analysis. Reflecting on the use of a qualitative data analysis program. Nurse Researcher. 18(3), 6-12.

Boyle, J.P., Thompson, T.J., Gregg, E.W., Lawrence, E.B., \& Williamson, D.F. (2010). Projection of the Year 2050 Burden of Diabetes in the US Adult Population: Dynamic modeling of incidence mortality, and pre-diabetes prevalence. Population Health Metrics. 8(29), 1-12.

Center for Disease Control and Prevention (2012). National Diabetes Surveillance System. Retrieved from: http://www.cdc.gov/diabetes/statistics/prev/national/menuage.htm 
Centers for Disease Control and Prevention. General Information and Estimates on Diabetes in the United States. National Diabetes Fact Sheet. (2011). U.S. Department of Health and Human Services. Atlanta, GA.

Center for Disease Control and Prevention (2010). Health United States, 2010. Retrieved from: http://www.cdc.gov/nchs/data/hus/hus10.pdf.

Centers for Disease Control and Prevention. National Diabetes Fact Sheets (2007). General information and national estimates on diabetes in the United States. U.S. Department of Health and Human Services. Atlanta, GA.

Chlebowy, D.O., Hood, S., LaJoie, A.S. (2010). Facilitators and Barriers to SelfManagement of Diabetes among Urban African American Adults. The Diabetes Educator. 36, 897- 905.

Delamater, A.M. (2006). Improving Patient Adherence. Clinical Diabetes. 24(2), 71-77. Diabetes Outreach (2009). A Guide to Diabetes Management. Diabetes Manual, $7^{\text {th }}$ Edition. Woodville, SA.

Diabetes Research Institute (2009). A Wellness Approach to Diabetes. Diabetes Education Services. Retrieved from: http://www.diabetesresearch.org. Ernst, E. (2002). Evidence is Incomplete on the Benefits and Risks of Commonly Used Herbal Medicines. A review. Retrieved from: www.evidencebasednursing.com. Famuyiwa, O.O. (1990). Important Considerations in the Care of Diabetes Patients in a Developing Country (Nigeria). Journal of Diabetic Medicine. 7, 927-930. 
Famuyiwa, O.O., Edozien, E.M., \& Ukoli, C.O. (1985). Social, Cultural, and Economic Factors in the Management of Diabetes Mellitus in Nigeria. African Journal of Medicine and Medical Science. 14(3-4), 145-154.

Gardiner P, Phillips R, Shaughnessy, A.F. (2008). Herbal and Dietary Supplement-Drug Interactions in Patients with Chronic Illnesses, American Family Physician. 77(1), 73-78.

Jovanovic, L. \& Harrison, R.W. (2004). Advances in Diabetes for the Millennium: Diabetes in minorities. Medscape General Medicine. 6(3 Suppl), 2.

Kiawi, E., Edwards, R., Shu, J., Unwin, N., \& Kamadjeu, R. (2006). Knowledge, Attitudes, and Behavior Relating to Diabetes and its Main Risk Factors among Urban Residents in Cameroon: A qualitative survey. Journal of Ethnicity \& Disease. 16(2), 503-509.

Lanting, L. C., Joung, I. M., Mackenbach, J. P., Lamberts, S. W., \& Bootsma, A. H. (2005). Ethnic Differences in Mortality, End Stage Complications, and Quality of Care among Diabetes Patients: A review. Diabetes Care. 28(9), 2280-2288.

Leininger, M.M. (1978). Transcultural nursing: Theories, research, and practice ( $2^{\text {nd }}$ ed.). New York: John Wiley.

Leininger, M.M. (1988). Leininger's Theory of Nursing: Cultural Care Diversity and Universality. Nursing Science Quarterly. 1, 152-160.

Leininger, M.M. (June, 1993). Transcultural Nursing Definition of Concepts/Constructs. The Transcultural Nursing Society Conference. Boston College School of Nursing, Boston, U.S.A. 
Lincoln, Y., \& Guba, E. (1985). Naturalist Inquiry. Beverley Hills, CA: Sage publications.

Locke, L. F., Spirduso,W.W., \& Silverman, S. J. (2000). Proposals That Work (4th ed.). Thousand Oaks, California: Sage.

Mbaya, J.K. (2010). Lay Beliefs of Type 2 Diabetic Patients: Thesis and Dissertations. Family Medicine: 42. University of Limpopo. Medunsa Campus. Mankweng, South Africa. Retrieved on 4/22/2013 from: http://hdl.handle.net/10386/547.

McGuigan, C. L. (2010). Diabetes in the Eritrean and Ethiopian Community: Cultural information and recommendations for diabetes educators. Retrieved from: http://ethnomed.org/clinical/diabetes/diabetes-in-the-eritrean-and Ethiopian community-cul.htm.

Medalie, J.H., Papier, C.M., Goldbourt, U., \& Herman, J.B. (1975). Major Factors in the Ddevelopment of Diabetes Mellitus in 10,000 Men. Archives of Internal Medicine.135(6):811-7. doi:10.1001/archinte.135.6.811.

Michael, P., Bryson, C.L., \& Rumsfeld, J.S. (2009). Medication Adherence. Its importance in cardiovascular outcomes. Circulation. 119, 3028-3035.

Migration Information Source (2011). African Immigrants in the United States. Migration Policy Institute. Retrieved from: http://migrationinformation.org/feature/display.cfm Migration Information Source (2012). African Immigrants in the United States. Migration Policy Institute. Retrieved from: http://www.immigrationpolicy.org/just facts/african-immigrants-america-demographic-overview. 
Miles, M. B., \& Huberman, A. M. (1994). Qualitative Data Analysis: An expanded sourcebook: Thousand Oaks, CA.

Nam, S., Chesla, C., Stotts, N.A., Kroon, L., \& Jason, S.L. (2011). Barriers to Diabetes Management: Patient and provider factors. Diabetes Research and Clinical Practice. 93, 1-9.

National Diabetes Education Programs (2009). The U.S. Department of Health and Human Services. NIH Publication No. 09-4343. NDEP-16. Retrieved from: http://www.ndep.nih.gov/media/guidprin_hc_eng.pdf.

Ndiaye, M. (2009). The Impact of Health Beliefs and Culture on Health Literacy and Treatment of Diabetes among French-speaking West African Immigrants. Master of Art, Thesis, Indiana University, Indianapolis. Retrieved from: https://scholarworks.iupui.edu/handle/1805/2050

Nwankwo, C.H., Nandy, B., \& Nwankwo, B.O. (2010). Factors Influencing Diabetes Management Outcome among Patients Attending Government Health Facilities in South east, Nigeria. International Journal of Tropical Medicine. 5(2), 28-36.

Osterberg, \& Blaschke, (2005). Adherence to Medication. New England Journal of Medicine. 353: 487-497.

Oza-Frank, R. \&. Venkat Narayan, K.M. (2010). Overweight and Diabetes Prevalence Among US Immigrants. Research and practice. American Journal of Public Health. 100(4), 661-668.

Polit, D., F., \& Beck, C., T. (2006). Essentials of Nursing Research: Methods, Appraisal, and Utilization. (6nd Ed.). Philadelphia: Lippincott Williams, \& Wilkins. 
Ryan, F., Coughlan, M., Cronin, P. (2007). Step-by-Step Guide to Critiquing Research. Part 2: Qualitative Research. British Journal of Nursing. 16(12), 738-744.

Schoenberg, N. E., Amey, C. H., \& Coward, R.T. (1998). Stories of Meaning: Lay perspectives on the origin and management of noninsulin dependent diabetes mellitus among older women in the United States. Social Science \& Medicine. 47(12), 2113-2125.

Schulze, M.B. \& Hu, F.B. (2005). Primary Prevention of Diabetes. What can be done and how much can be prevented? Annual Reviews Public Health. 26, 445-467.

Shenolikar, R.A., Balkrishman, R., Camacho, F.T., Whiteman, J.T., \& Anderson, R.T. (2006). Race and Medication Adherence in Medicaid Enrollees with Type 2 Diabetes. Journal of the National Medical Association. 98(7), 1071-1077.

Shepard, R. M. (2008). Cultural Adaptation of Somali Refugee Youth. New York: LFB Scholarly Publishing LLC.

Siegel, J. E., Horan, S. A., \& Teferra, T. (2001). Health Care Status of African-Born Residents of Metropolitan Washington, DC. Journal of Immigrant Health. 3(4), 213-224.

Skyler, J.S. (2004). Effects of Glycemic Control on Diabetes Complications and on the Prevention of Diabetes. Clinical Diabetes. 22(4), 162-166.

Strauss, Anselm \& Corbin, J. (1998). Basics of Qualitative Research: Techniques and Procedures for developing grounded theory. Thousand Oaks, California: Sage. 
Stettler, C., Allemann, S., Juni,P., Cull, C.A., Holman, R.R., Egger, M., Krahenbuhl, S., \& Diem, P. (2006). Glycemic Control and Macrovascular Disease in Type 1 and Type 2 Diabetes Mellitus. Meta-analysis of randomized trials. Americam Heart Journal. 152(1), 27-37.

Tong, A., Sainsbury, P., \& Craig, J. (2007). Consolidated Criteria for Reporting Qualitative Research: COREQ. International Journal For Quality in Health Care. 9(6), 349-357.

Uitewaal, P.J., Manna, D.R., Bruijnzeels, M.A., Hoes, A.W., \& Thomas, S. (2004). Prevalence of Type 2 Diabetes Mellitus, other Cardiovascular Risk Factors, and Cardiovascular Disease in Turkish and Moroccan immigrants in North West Europe: a Systematic review. Preventive Medicine. 39(6):1068-1076.

doi:10.1016/j.ypmed.2004.04.009.

United States Census Bureau (2010). Census 2010 News. Retrieved from: http://2010.census.gov/news.

United States Department of Health and Human Services (1999). Improving the Collection and Use of Racial and Ethnic Data in HHS. Joint report of the HHS data council working group on racial and ethnic data and the data work group of the HHS initiative to eliminate racial and ethnic disparities in health. Retrieved from: http://aspe.hhs.gov/datacncl/racerpt/intro.htm.

U.S. Office of Minority Health (2010). Diabetes and African Americans. U.S. Department of Health and Human Services. Retrieved from: http://minorityhealth.hhs.gov. 
Utz, S.W., Steeves, R.H., Wenzel, J., Hinton, I., Jones, R.A., Andrews, D., Murphy, A., \& Oliver, M.N. (2006). "Working Hard with It": Self-management of Type 2 Diabetes by Rural African Americans. Family \& Community Health. 29(3), 195- 205.

Venelda-Carr, C. (2012). Minority Ethnic Groups with Type 2 Diabetes. The importance of effective dietary advice. Journal of Diabetes Nursing. 16(3), 88-96.

Weber, R.P. (1990). Basic Content Analysis. Newbury Park, CA. Sage Publications. World Health Organisation (2001). Legal Status of Traditional Medicine and Complementary/Alternative Medicine: A Worldwide Review, p. 33-35. World Health Organization (2008). Fighting Non-Communicable Diseases. Africans' new Silent Killers. WHO Regional Office for Africa. African Health Monitor. 8(1), 1-60. Retrieved from: http://ahm.afro.who.int.

World Health Organization (2010). Overview of Traditional Medicine in ECOWAS Member States. WHO Regional Office for Africa. African Health Monitor. 13(2). Retrieved from: http://ahm.afro.who.int/issue13/HTML/article2.html.

Yusuff, K.B., Obe, O., \& Joseph, B.Y. (2008). Adherence to Anti-Diabetes Drug Therapy and Self-Management Practices among Type 2 Diabetics in Nigeria. Pharmacy World Science. 30, 876-883. 


\section{Appendix A}

\section{Demographics Questionnaire}

Please select the applicable options:

1. Age

$18-30()$

$31-40()$

$41-50()$

$51-60()$

$>60()$

2. Gender: Male () Female ()

3. Country of birth:

4. Year of Migration to the United States:

$<1991()$

$1991-2000()$

2001-2009 ( )

2010>( )

5. Religion:

Christian ( ) Muslim ( ) Other ( ) 
6. Education level:

No formal education ( )

Primary ( )

Secondary ( )

University/Tertiary ( )

7. Employment status:

Student ( )

Employed ( )

Unemployed ( )

Unable to work ( )

8. Household situation:

Couple with children at home ( )

Couple without children ( )

Single parent with children at home ( )

Living alone ( )

Others ( )

9. Type of diabetes

Type 1( ) Type 2 ( ) Don’t know ( ) 
10. Duration of diabetes (years)

$1-5()$

$6-10()$

$11-15()$

$>15$ ( )

11. Family history of diabetes?

Yes ( ) No ( ) Don’t know ( )

12. Complications related to diabetes

Eyes ( ) Feet/lower extremity ( ) Hypertension ( ) Kidney ( )

No known complication(s) ( )

13. Do you have health insurance?

Yes ( ) No ( )

14. When was the last time you were able to talk with a nurse or doctor about diabetes? 


\section{Appendix B}

\section{Interview Questions}

1. Tell me about how you found out you had diabetes. What was that like?

2. Can you describe what your care was like after you found out?

3. I am wondering if you had diabetes education-what was, that like for you.

4. What kind of relationship do you have with your health care provider? Were you able to ask questions about your diabetes? Medications, diet, and exercise? Did your provider answer your questions in a way that you understood? Can you please share with me 3 examples?

5. Did your provider/educator help you to figure out how to eat in a healthy way with foods that are eaten in your culture?

6. Tell me what medications you are taking for diabetes. How do they work? How much do you take? How often do you take your medications? Do you understand how to take each of them safely? Did anyone ever try to teach you? Do you ever run out?

7. Besides taking medication, in what other ways have you tried to take care of your diabetes?

8. Were you able to get the things you need to stay healthy with diabetes: such as a glucose meter and strips, medications, orthopedic shoes if needed, healthy foods? 9. What do you do for exercise? Is it safe to exercise in your neighborhood, can you go for a walk without worry? 
10. Can you understand the language that your provider speaks? Can he/she understand you? Do you understand it very well, well, kind of, not at all? Did you have an interpreter? Was your interpreter a family member or a professional? If you used a family member, were you comfortable sharing all of your information or did you hold back some because you did not want them to hear private info?

11. In what ways has your thinking changed regarding diabetes since you were first diagnosed?

12. I want to find out if there are things that get in the way of proper diabetes care for you. What can you share about your experience that would help me to understand the barriers that West African immigrants who are diagnosed with diabetes face? 


\section{Appendix C}

\section{CONSENT DOCUMENT}

\section{Rhode Island College}

\section{AN EXPLORATION OF THE BARRIERS TO DIABETES MANAGEMENT AMONG WEST AFRICAN IMMIGRANTS}

My name is Oluseyi Abioye-Akanji. I am a student in the Master's program at Rhode Island College School of Nursing. I am conducting a study to learn about West African's experience with diabetes management in Rhode Island. The name of my supervisor is Doctor Peggy Matteson. She may be reached at pmatteson@ric.edu. Please read this entire form and ask any questions you have before deciding whether to be in the study.

\section{Background Information}

The study will help me to understand the factors that affect diabetes management among West African immigrants in Rhode Island.

I am asking you to participant because:

- You are a recent West African immigrant from Nigeria, Ghana, or Liberia.

- You are age 18 or older

- You have been told you have Type 1 or Type 2 diabetes

- You are not pregnant

- You are able to speak, understand, and read English

\section{Procedures}

If you choose to take part in the study, first you will fill out a form that asks about you and then we will have a conversation during which I will ask you to answer questions about your experiences in managing your diabetes since you came to Rhode Island. The interview may 
take place in a room at the African Alliance of Rhode Island, at 570 Broad Street in Providence. It may also take place at any public location of your choice.

The interview will take about 90 minutes. I will tape the interview so I can remember all your answers after the interview. If you do not want to answer questions on the form or any of the questions that I ask you, it is fine. I will skip the question.

\section{Risks of Being in the Study}

The main risk of participating in this study is that sharing personal health information or talking about your health care experiences may remind you of difficult situations you have experienced in the past. If this should happen you may choose to not answer a question and continue the interview or to stop the interview and leave. That will be fine. If you wish to discuss the issues with someone, I will give you a list of resources that you can contact, including the Providence Community Health Centers and the RI Free Clinic.

\section{Benefits to You}

The study will not benefit you directly.

Initial here to indicate that you have read and understand this page RIC Institutional

Review Board Matteson/Aioye-Akanji Consent Form Approval \# 1213-38 Page 2 of 3 Version 2/16/2013 Expiration date 2/17/2014

\section{Voluntary Participation}

It is your choice to participate or not participate in all or part of this study. You will not be punished if you choose not to be a part of this study or to not answer some questions. If you choose to participate, you can withdraw from the study at any time without any problem. It will not affect your healthcare.

\section{Confidentiality}


I will not tell anybody that you have talked to me. Your name will not be written down or mentioned on the audio recording, and your name will not be mentioned when I write about the study.

I will keep the records obtained during our interview in a locked file. My supervisor can review the records and will also keep your information confidential. In rare cases the Rhode Island College Institutional Review Board (IRB) may choose to look at the records, but your name and other possible identifiers will not be there. The Rhode Island College IRB is responsible for protecting the interests of research participants like you. All information will be kept locked up for three years after which all notes and tapes will be destroyed.

\section{Contacts and Questions}

If you have any question about me or about the study, you may contact me at 401-301-2437, or send me an email at oabioye_9508@ric.edu. You can also contact my supervisor Dr Peggy Matteson at 401-456-4779 or send her an email at pmatteson@ric.edu.

If you think I did not treat you fairly or would like to talk to someone else about your rights and safety as a participant in the study, please contact Dr. Christine Marco, Chair of the Rhode Island College Institutional Review Board at IRB@ric.edu, or by phone at 401-4568598. You can also send mail to her mail by writing to Dr. Christine Marco, Chair IRB; c/o Department of Psychology, Horace Mann Hall 311; Rhode Island College; 600 Mount Pleasant Avenue; Providence, RI 02908. A copy of this form will be given to you for your own records.

Initial here to indicate that you have read and understand this page RIC Institutional

Review Board Matteson/Aioye-Akanji Consent Form Approval \# 1213-38 Page 3 of 3 Version 2/16/2013 Expiration date 2/17/2014

\section{Statement of Consent}


I have read and I understand this form, and I agree to participate in the research study " $A N$ EXPLORATION OF THE BARRIERS TO DIABETES MANAGEMENT AMONG WEST AFRICAN IMMIGRANTS. ” I understand that my participation is voluntary and I can withdraw at any time with no punishment. I have received answers to the questions I have asked. I will contact the researcher with any future questions that may arise. I am at least 18 years of age.

I__ agree ___ do not agree to be audio taped for this study.

Printed name of participant

Signature of Participant Date

Name of researcher obtaining consent 